\title{
Moist wound healing after mast cell tumor surgical removal in a dog
}

\author{
Boris Semenov, Anna Nazarova*, Tatiana Kuznetsova, Maria Sergeeva, and Anna \\ Kozitcyna \\ Saint-Petersburg State University of Veterinary Medicine, 196084 Saint-Petersburg, Russia
}

\begin{abstract}
Study of various wound healing methods is a relevant issue of modern veterinary medicine. One of the investigated methods of wound healing is moist wound healing in a hydrated environment using hydrogel patches. In described clinical case, an eight-year-old female American Pit Bull Terrier was subjected to mast cell tumor surgical removal on the left hindlimb. During the patient postoperative treatment, Sorbalgon ${ }^{\circledR}$, Hydrocoll ${ }^{\circledR}$ and HydroClean ${ }^{\circledR}$ dressings were used to protect the surgical site and maintain high moist environment in the wound. The dressings absorbed wound exudate and stimulated both the surgical site cleansing and the granulation tissue formation, made it possible to heal large wound on the limb without the keloid scar development.
\end{abstract}

\section{Introduction}

Study of various wound healing methods is a relevant issue of modern veterinary medicine. One of the investigated methods of wound healing is moist wound healing in a hydrated environment using hydrogel patches.

Established that during moist wound healing proliferative processes are stimulated and the time for onset of wound epithelization is reduced [1].

Water and moisture supports viability and function activity of all body cells. Only in moist environment cells remain alive and are able to reproduce and thus the wound healing occur. The idea of moist wound healing originated in 1962, when George Winter established that wound epithelialization is accelerated twice in moist environment compared to dry healing under a scab [2]. In addition, with moist healing, the optimal temperature in the injury is maintained and the possibility of re-infection is reduced.

Wound healing processes researchers are noting platelet concentrate (sodium citrate based) [3-5], phytochemical compounds from plants of the genus L. Ferrea [6] and allogeneic stem cell transplantation [7] generate a positive effect on wound healing response from the biological point of view. The low-level laser therapy for wounds treatment also showed possibility to achieve wound healing in a shorter time due to selection of the right parameters combination [8].

Nowadays, one of the main modern medicine issues is the development of local treatment methods for wounds of different etiology [9].

\footnotetext{
* Corresponding author: anna.v.nazarova@mail.ru
} 
In order to solve this problem, intensive scientific work is carried out to research the effects of wound dressings, such as Sorbalgon ${ }^{\circledR}$, Hydrocoll® , and HydroClean ${ }^{\circledR}$ plus. These wound dressings are designed to protect and maintain an optimal moist wound environment, absorb wound exudate, stimulate wound debris cleansing and promote the granulation tissue formation, thereby accelerating the wound healing processes.

The best healing conditions are created by moisture-retaining hydrocolloid dressings that do not disturb the wound tissues [10].

The aim of this work was to evaluate the Sorbalgon ${ }^{\circledR}$, Hydrocoll ${ }^{\circledR}$ and HydroClean ${ }^{\circledR}$ plus dressings use to create a moist environment for the postoperative wound treatment.

\section{Materials and methods}

The object of research was an eight-year-old female American Pit Bull Terrier, weight 33 $\mathrm{kg}$, vaccinated, neutered, feeding: commercial feeds. The owners referred to the "Bars" veterinary clinic due to the tumor formation on the left hindlimb. The mass was dramatically increased in size over the past month. At the time of the first visit, the tumor diameter was $15 \mathrm{~mm}$.

The fine-needle biopsy was carried out and after the sample examination a highly differentiated mast cell tumor was diagnosed. Round cells with a high nuclear index, large numbers of purple cytoplasm granules and atypical mitoses were identified during the cytological examination of the biopsy. According to the laboratory blood test results, an ESR increase to $14 \mathrm{~mm} / \mathrm{h}$ (reference values $2-6 \mathrm{~mm} / \mathrm{h}$ ), the activity of blood serum alkaline phosphatase was $931 \mathrm{U} / \mathrm{l}$ (reference values 10-150 U/1) and slight increase in serum urea level - $7.79 \mathrm{mmol} / \mathrm{l}$ (reference values $3.5 \mathrm{mmol} / \mathrm{l}-7.5 \mathrm{mmol} / \mathrm{L}$ ) were established.

On 12.08.20, mast cell tumor surgical removal was performed. Horizontal mattress stitches were applied to pull the skin edges closer. The corners of the surgical wound were sutured tightly; the wound middle part was sutured with rollers without the complete wound defect closing. Hydrogel wound dressings Sorbalgon ${ }^{\circledR}$, Hydrocoll ${ }^{\circledR}$ and HydroClean ${ }^{\circledR}$ plus were used at different stages of the surgical wound healing process.

\section{Results and discussion}

On 13.08.20 during the wound examination the signs of ischemia of the skin between the sutures and the edge of the wound were noted (figure 1).

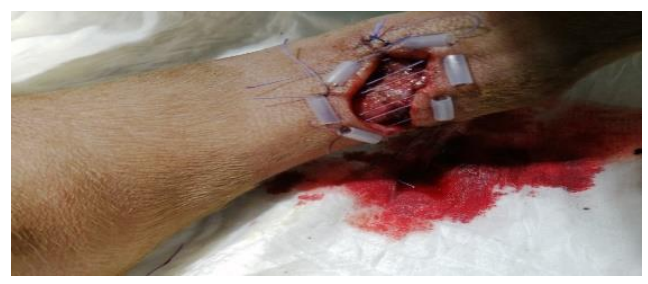

Fig. 1. Horizontal mattress tensioning sutures

The wound was cleaned with $0.05 \%$ chlorhexidine hydrous solution and an adsorbent Sorbalgon ${ }^{\circledR}$ wound dressing was applied. This wound dressing is recommended for the $1 \mathrm{st}$ stage (exudative) of the wound process.

For the next two days, the wound was treated according to this scheme. During examination, there was poor exudation in the wound open area.

On 16.08.20 was decided to remove the tensioning sutures. After the sutures were removed, ischemic areas with strong impressions were noted along the wound edges. The 
distal wound edge was almost completely closed due to adhesive inflammation with the underlying tissues. The proximal wound edge was partially adhered to the underlying tissues. It was decided to achieve wound healing by secondary intention.

Local allergic reaction to $0.05 \%$ chlorhexidine hydrous solution was noted, so a $0.9 \%$ sodium chloride solution was used for wound cleaning further. From 16.08 to 20.08 the wound dressing was performed daily with saline solution, followed by Sorbalgon ${ }^{\circledR}$ wound dressing application.

On 20.08.20 the corner sutures of the surgical wound removal was performed. There were no signs of skin edges fusion. After careful wound irrigation under pressure, instead of the Sorbalgon ${ }^{\circledR}$ wound dressing, a self- adhesive hydrocolloid dressing Hydrocoll ${ }^{\circledR}$ was used. This wound dressing is optimal for the 2nd stage (granulation) of the wound process.

After three days during the control check-up satisfactory granulation of the wound was noted, the wound edges were pink, the serous discharge was abundant (figure 2).

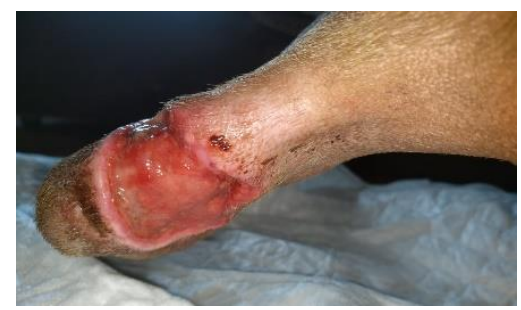

Fig. 2. Wound condition on 25.08.20 (13 days after surgery)

Due to the local allergic reaction to the adhesive patch base at the site of the attachment, from 25.08.20 a HydroClean ${ }^{\circledR}$ plus adhesive wound dressing was used. This wound dressing gave a significant improvement in the condition of the wound after the first day (figure 3).

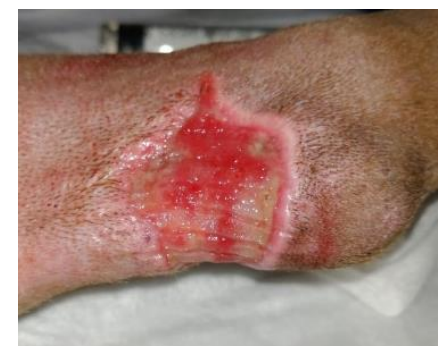

Fig. 3. Wound condition on 26.08.20 (14 days after surgery)

After that, HydroClean ${ }^{\circledR}$ plus dressing renewal was prescribed once every three days. During the check-ups satisfactory wound tissue granulation formation was noted with the forming of homogeneous soft small granulations and marginal epithelization of the wound without the rough scar development (figure 4).

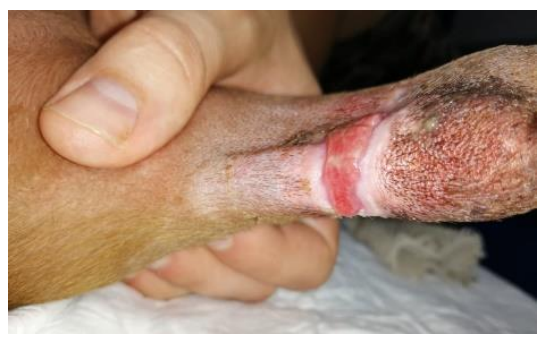

Fig. 4. Wound condition on 03.09.20 (22 days after surgery) 
When wound dressing was changed once every three days, satisfactory granulation and active wound epithelialization were observed (figures 5, 6, 7).

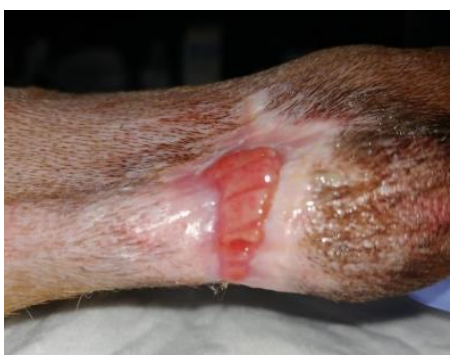

Fig. 5. Wound condition on 06.09.20 (25 days after surgery)

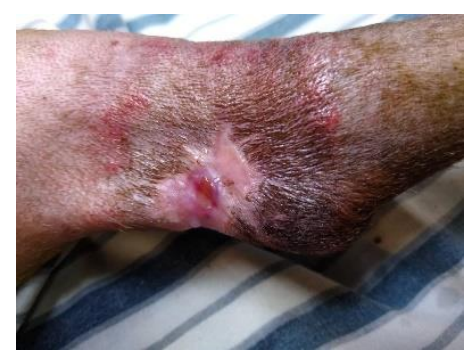

Fig. 6. Wound condition on 17.09.20 (36 days after surgery)

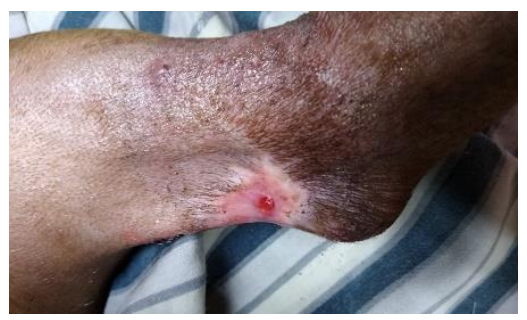

Fig. 7. Wound condition on 20.09.20 (39 days after surgery)

At the control check-up on 27.09.20, the condition of the wound was good, the granulations were small, and the skin epithelization was favorable. Also there was unhealed site the size of $2 \times 2 \mathrm{~mm}$ (figure 8 ).

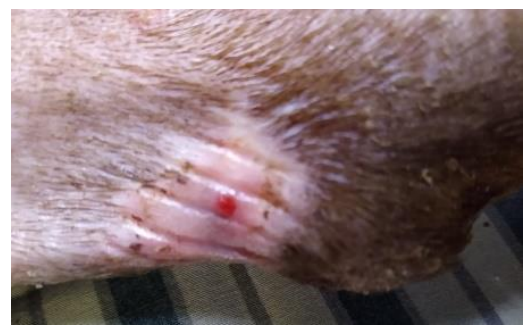

Fig. 8. Wound condition on 27.09.20 (46 days after surgery)

On 01.10.20 complete wound healing was observed without the formation of a constricting scar (figure 9). 


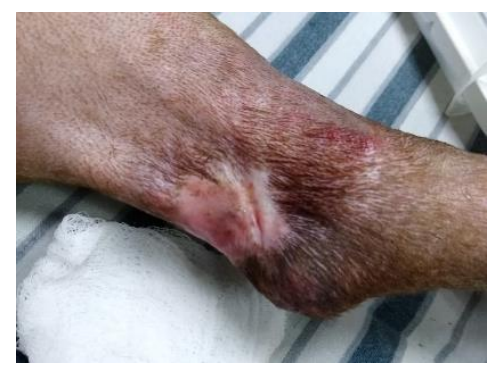

Fig. 9. Complete wound healing on 01.10 .20 (50 days after surgery)

In described clinical case, the method of moist wound healing by secondary intention was chosen. The choice of wound local treatment was determined by the wound process stage, associated complications and individual characteristics of the patient [11]. After clearing the wound surface of fibrin, reducing perifocal inflammation and exudation, the granulation tissue and epithelial islands formation, at the stages of proliferation and epithelization, the treatment purposes were: creating optimal conditions for regeneration, mechanical protection of new-forming connective tissue, accelerating the formation and retraction of scar tissue. The main part of modern local wound treatment is the items and products that create and maintain environment close to physiological conditions, in this case to ensure wound healing by a moist and humid environment.

Hydrocolloid dressings structure is a polyurethane sponge or film coated with a hydrophilic colloid: gelatin, cellulose or pectin, dispersed in an adhesive mass.

Working principle of this coating type is the transformation of the colloid into a gel under the action of the released wound exudate during the contact with the wound surface. In this way, the excess exudate is removed with the wound dressing while maintaining a moist environment [10].

Wound healing in the presented case was complicated by the following factors:

- wound localization. The tarsal joint is one of the synovial joints that provide locomotion of the limb;

- during the postoperative period, ischemia of the skin edges around the wound and the adhesion of the skin and muscles began (due to the lack of a pad between the skin and the muscles, which is used when applying tensioning sutures). This made it impossible to further stretch the skin to close the defect.

Based on healing features and wound topography the three types of dressings were chosen as the most suitable and optimal options for moist environment establishing.

Sorbalgon ${ }^{\circledR}$ is a sterile disposable wound dressing consisting of calcium alginate fibers, which, after contact with sodium salts of blood and wound fluid, are transformed into a hydrophilic gel. When the insoluble calcium alginate is contacted with the wound exudate, it is replaced by sodium ions present in the wound exudate or blood serum, a soluble sodium salt is formed, and a hydrophilic gel is build. The process of converting waterinsoluble calcium alginate into water-soluble sodium alginate allows absorbing a large amount of fluid released from the wound. Because of the non-woven dressing material combined with its physical and chemical properties the dressing has a high absorbency, which is especially important in the wounds treatment involving medium and heavy exudation.

HydroClean ${ }^{\circledR}$ plus is a superabsorbing hydroactive wound dressing with the antiseptic poly-hexamethylene-biguanide (PHMB). The central part of dressing contains superabsorbing polyacrylate (SAP) embedded in fluff pulp. Activated by Ringer's solution, SAP is bound to the antibacterial agent PHMB. The wound contacting layer knitted polypropylene fabric with silicone strips applied, which additionally counteract the bandage 
adhesion to the wound. The waterproof polypropylene film on the outside of the bandage prevents the dressing from drying out prematurely, so the wound can be kept moist for up to 3 days.

Hydrocoll ${ }^{\circledR}$ is a self-adhesive hydrocolloid dressing with a semi-permeable top layer that prevents the penetration of microorganisms and water. By converting hydrocolloid particles into gel, the dressing promotes moist environment formation in the wound, accelerates wound purification, and stimulates the granulation and epithelialization processes.

Despite the quite high mobility of the wound location, these types of dressings held well at the place of attachment. During the application of a dressings combination, a positive wound healing dynamics in a moist environment was noted.

\section{Conclusion}

Presented study showed that Sorbalgon ${ }^{\circledR}$, Hydrocoll ${ }^{\circledR}$ and HydroClean ${ }^{\circledR}$ plus wound dressings protect and maintain optimal moist wound environment, absorb wound exudate and stimulate wound cleansing and granulation tissue formation, thereby accelerating wound healing. These dressings improve the processes of reparative regeneration, prevent the formation of keloid scars and improve metabolic processes and trophism of tissues.

HydroClean ${ }^{\circledR}$ plus wound dressing provides wound cleansing through the "washabsorb" mechanism by continuously releasing Ringer's solution into the wound and absorbing the wound exudate. The antiseptic poly-hexamethylene-biguanide (PHMB), bound in the core with superabsorbing polyacrylate (SAP), acts antibacterial and inhibits the growth of microorganisms inside the pad of the dressing, preventing re-infection of the wound. Superabsorbing polyacrylate (SAP) inactivates matrix metalloproteinases (MMP), which inhibit the wound healing process, which in turn provides faster wound healing.

\section{References}

1. A.S. Luzan, I.YU. Aref'ev, I.A. Klemenova, N G. Zaseckaya, P.V. Peretyagin, Bulletin of Surgery, 179, 39 (2020)

2. G. D. Winter, Scab formation and epithelialization rate of superficial wounds on the skin of a young domestic pig Nature, 193, 293 (1962)

3. B. Semenov, T. Kuznetcova, V. Guseva, Clinical cases VetPharma, 4 (2015)

4. L.S. Americo, A. Vanessa, N.K. Mendes, Frontiers in veterinary science, 7, 244 (2020)

5. D. Dalgin, Y. Meral, M. Cenesiz, C. Esin, B.U. Sayilkan, U. Ozcan, Z.N. Colak, E. Kulluk, Veterinary Medicine-Veterinary medicine-Science and practice, 76(11), 638 (2020)

6. N. Kim, K.U. Choi, Histology And Histopathology, 35(7), 757 (2020)

7. N. Enciso, L. Avedillo, M.L. Fermin, Stem Cell Research \& Therapy, 11(1), 261 (2020)

8. N. Kampa, S. Jitpean, S. Seesupa, S. Hoisang, Veterinary World, 13(7), 1417 (2020)

9. V.L. Kuznecova, A.G. Solov'eva, S.P. Peretyagin, O.V. Kostina, M.V. Presnyakova, P.V. Peretyagin, A.S. Luzan, Herald of new medical technologies, 24(3), 104 (2017)

10. A.M. Morozov, A.N. Sergeev, N.A. Sergeev, G.A. Dubatolov, S.V. Zhukov, K.I. Gorodnichev, M.M. Muravlyanceva, D.D. Suhareva, Modern problems of science and education, 2, 167 (2020)

11. M.V. Aralova, Herald of new medical technologies, 20(2), 25 (2013) 